\title{
PENGARUH PENGUASAAN PSIKOLOGI PEMBELAJARAN TERHADAP PENINGKATAN KOMPETENSI GURU PENDIDIKAN AGAMA ISLAM
}

\author{
Mustahidang Usman ${ }^{1}$, Nurhidaya $\mathbf{M}^{2}$ \\ ${ }^{*}$ Pendidikan Agama Islam Fakultas Agama Islam| Unismuh Makassar \\ ${ }^{* 2}$ Pendidikan Agama Islam Fakultas Agama Islam| Unismuh Makassar
}

\begin{abstract}
ABSTRAK
Jenis penelitian adalah penelitian Survey dengan pendekatan metode kuantitatif dengan mengeksplorasi data dilapangan dengan metode analisis deskriktif kuantitatif. Mengingat bahwa populasi guru di sekolah ini kurang dari 100 orang guru maka penetapan sampel pada penelitian ini adalah sampel populasi atau keseluruhan dari populasi yaitu 18 guru. Hasil penelitian ini menunjukkan bahwa Penguasaan psikologi pembelajaran terhadap peningkatan kompetensi guru Pendidikan Agama Islam di SMA Muhammadiyah Sungguminasa Kabupaten Gowa yaitu Bahwa penguasaan psikologi pembelajaran, mulai dari memahami siswa sebagai pelajar, memilih metode yang sesuai keadaan peserta didik, membantu peserta didik yang kesulitan dalam belajar dan lain sebagainya, sangat dituntut untuk dimiliki oleh seorang guru, agar seorang guru dapat menciptakan suasana pembelajaran yang kondusif dan efektif. Tingkat kompetensi guru Pendidikan Agama Islam di SMA Muhammadiyah Sungguminasa Kabupaten Gowa yaitu sudah baik, terbukti dari pemahaman guru tersebut tentang 4 rana kompetensi ( paedagogik, sosial, kepribadian, dan profesional) yang cukup luas dan penilaian dari rekan-rekan guru tentang kompetensi yang dimilikinya yang mencapai 97,2 \% atau 16 orang guru menjawab baik.
\end{abstract}

\section{Kata Kunci : Psikologi Pembelajaran Kompetensi Guru}

\begin{abstract}
The type of research was survey research with quantitative method approach by exploring field data with quantitative descriptive analysis method. Given that the teacher population in this school was less than 100 teachers then the determination of the sample in this study was the sample population or the entire population of 18 teachers. The results of this study indicate that the mastery of learning psychology on improving the competence of teachers of Islamic Education in SMA Muhammadiyah Sungguminasa Gowa District that was mastery of learning psychology, ranging from understanding students as students, choosing methods appropriate to the state of learners, helping learners who have difficulty in learning and etc., was required to be owned by a teacher, so that a teacher can create a conducive and effective learning atmosphere. The level of competence of teachers of Islamic Education in SMA Muhammadiyah Sungguminasa Gowa District was good, proven from the teacher's understanding of the 4 broadest range of competence (paedagogic, social, personality, and professional), and the assessment from the teachers about their competence reached $97.2 \%$ or 16 teachers answered well.
\end{abstract}

Keywords: Psychology of Teacher Competency Learning 


\section{PENDAHULUAN}

Dunia pendidikan sedang diguncang oleh berbagai perubahan dengan tuntutan dan kebutuhan masyarakat, serta ditantang untuk dapat menjawab bebagai permasalahan lokal dan dan perubahan global yang begitu pesat. Perubahan dan permasalahan tersebut seperti pasar bebas, perkembangan ilmu pengetahuan, teknologi dan informasi, seni, budaya, yang sangat dahsyat. Maka dengan perkembangan tersebut harus dibarengi dengan perkembangan di dunia pendidikan mulai dari mutu pendidikan baik mutu guru, siswa, kurikulum, dan sarana prasarana yang berkualitas, sehingga akan mengahsilkan sumberdaya manusia yang berkualaitas pula.

Dalam meningkatakan kualitas pendidikan dipengaruhi oleh penyempurnaan seluruh komponen pendidikan seperti peningkatan kualitas dan pemerataan penyebaran guru, kurikulum yang disempurnakan, sumber belajar, sarana dan prasarana, kebijakan pemerintah. Namun disini guru merupakan komponen paling menentukan, karena ditangan gurulah komponen-komponen lain menjadi sesuatu yang berarti bagi kehidupan peserta didik. Guru pula yang menjadi perhatian utama bagi peserta didik sehingga guru harus bisa menjadi sosok figur bagi anak didiknya. Oleh sebab itu, guru harus memiliki empat kompetensi yaitu kompetensi pedagogik, kompetensi personal, kompetensi profesional, dan kompetensi sosial.

Implementasi kompetensi di atas dalam proses pembelajaran meniscayakan kepemilikan pengetahuan tentang psikologi, karena proses pembelajaran merupakan situasi psikologis.

Peningkatan kompetensi mengajar merupakan suatu keniscayaan. Salah satu aspek penting dalam upaya peningkatan kompetensi adalah bagaimana menimplementasikan dan memaksimalkan peran psikologi dalam mengelolah kegiatan pembelajaran. Untuk dapat mewujudkan hal tersebut, perlu memahami berbagai aspek psikologi khususnya psikologi pembelajaran.

$$
\text { Kegiatan pembelajaran, }
$$
termasuk pembelajaran Pendidikan 
Agama Islam (PAI), sarat dengan muatan psikologis. Dalam proses pembelajaran, pendidikan agama islam terjadi interaksi antara guru (pendidik dan siswa (peserta didik). Dalam interaksi itu, terdapat peristiwa dan proses psikologis. Peristiwa dan proses psikologis ini sangat perlu untuk dipahami dan dijadikan rambu-rambu oleh guru dalam memperlakukan peserta didik secara tepat. Para guru termasuk guru agama di setiap institusi pendidikan, sangat diharapkan memiliki bahkan dituntut untuk menguasai pengetahuan psikologi pembelajaran.

Berdasarkan problem pokok yang disebutkan dalam judul ini yakni Pengaruh Psikologi Pembelajaran Terhadap Peningkatan Kompetensi Guru Pendidikan Agama Islam di SMA Muhammadiyah Sungguminasa Kabupaten Gowa, maka penulis mengangkat permasalahan sebagai berikut:

1. Bagaimana Penguasaan

Psikologi Pembelajaran Guru Pendidikan Agama Islam di SMA Muhammadiyah Sungguminasa Kabupaten Gowa?
2. Bagaimana Tingkat Kompetensi Guru Pendidikan Agama Islam di SMA Muhammadiyah Sungguminasa Kabupaten Gowa?

3. Bagaimana Pengaruh Penguasaan Psikologi Pembelajaran Terhadap Peningkatan Kompetensi Guru Pendidikan Agama Islam di SMA Muhammadiyah Sungguminasa Kabupaten Gowa?

\section{METODE PENELITIAN}

Jenis penelitian ini adalah penelitian survei (lapangan) dengan penelitian non eksperimen dengan pendekatan kuantitatif, yaitu jenis penelitian yang penyajiannya dalam bentuk angka untuk mengetahui data maupun untuk membandingkan dengan data lain, dan di analisis dengan penelitian yang bersifat deskriptif kuantitatif yaitu untuk menggambarkan pengaruh penguasaan psikologi pembelajaran terhadap peningkatan kompetensi guru Pendidikan Agama Islam di SMA Muhammadiyah Sungguminasa Kabupaten Gowa. 
Tabel I

\section{Keadaan populasi sekaligus Sampel}

\begin{tabular}{|c|c|c|c|c|}
\hline \multirow{2}{*}{ No } & \multirow{2}{*}{$\begin{array}{c}\text { Kepala } \\
\text { Sekolah, Guru } \\
\text { dan Tata } \\
\text { Usaha }\end{array}$} & \multicolumn{2}{|c|}{$\begin{array}{c}\text { Jenis } \\
\text { kelamin }\end{array}$} & \multirow{2}{*}{ Jumlah } \\
\hline & & LK & PR & \\
\hline 1. & Kepala Sekolah & 1 & & 1 \\
\hline 2. & Guru & 7 & 8 & 15 \\
\hline \multirow[t]{2}{*}{3.} & Staf Tata Usaha & & 2 & 2 \\
\hline & Jumlah total & 8 & 10 & 18 \\
\hline
\end{tabular}

Instrumen penelitian data pada penelitian ini dilakukan melalui wawancara, observasi di kelas, metode angket, dan dokumentasi. Untuk mendapatkan data yang akurat dalam penulisan ini, penulis menggunakan cara sebagai berikut : Wawancara, Observasi, Angket dan Dokumentasi.

Teknik analisis data yang digunakan penulis dalam penulisan ini adalah teknik analisis deskriptif kuanlitatif, digunakan untuk menganalisis data yang bersifat non eksperimen dan data dari hasil sebaran angket di analisis dengan langkahlangkah sebagai berikut:

1) Tabulasi frekuensi berdasarkan hasil penelitian

2) Menentukan presentasi hasil penelitian dengan rumus sebagai berikut:

$$
\mathrm{P}=\frac{f}{N} \times 100 \%
$$

Ket:F $=$ Frekuensi hasil penelitian

$$
\begin{aligned}
& \mathrm{N}=\text { Jumlah Sampel } \\
& \mathrm{P}=\text { Angka Presentasi }
\end{aligned}
$$

\section{HASIL DAN PEMBAHASAN PENELITIAN}

\section{Penguasaan Psikologi Pembelajaran \\ Guru Pendidikan Agama Islam}

Guru agama dalam proses Pendidikan Agama Islam, sangat diharapkan mampu menciptakan suasana pembelajaran yang kondusif agar memungkinkan para siswa mengikuti proses belajar dengan tenang dan bergairah. Guru Pendidikan Agama Islam, selaku tenaga profesional yang menguasai psikologi pembelajaran tentu memiliki kepribadian yang mantap, arif, dan bijaksana sehingga peserta didik yang bermasalah dalam pembelajaran dapat diarahkannya dengan baik sesuai kemauan peserta didik, selain itu guru PAI yang menguasai psikologi pembelajaran juga dapat menyusun pembelajarn sesuai dengan 
kemampuan peserta didik yang berbeda-beda, memilih metode yang sesuai keinginan peserta didik juga salah satu konstribusi tersendidi bagi guru PAI yang menguasai psesrta didik. Pentingnya penguasaan psikologi pembelajaran bagi seorang guru, terutama guru Pendidikan Agama Islam dikarenakan pembelajaran Pendidikan Agama Islam itu sangat sarat dengan muatan psikologis. Yang apabila seorang guru mengabaikan aspek-aspek psikologis dalam pembelajaran akan berakibat kegagalan, sehingga tujuan pembelajaran tidak tercapai.Berikut ini gambaran dalam bentuk tabulasi angket tentang bagaimana penguasaan psikologi pembelajaran guru Pendidikan Agama Islam di SMA Muhammadiyah Sungguminasa Kabupaten Gowa, sebagai berikut :

Tabel II Daftar Distribusi Frekuensi Tanggapan Responden Guru

\begin{tabular}{|l|l|c|c|}
\hline NO & $\begin{array}{l}\text { Alternatif } \\
\text { Jawaban }\end{array}$ & $\begin{array}{c}\text { Frekue } \\
\text { nsi }\end{array}$ & $\begin{array}{c}\text { Persent } \\
\text { ase (\%) }\end{array}$ \\
\hline 1. & Paham & $\mathbf{1 6}$ & $\mathbf{8 8 , 9 \%}$ \\
\hline 2. & Kurang Paham & $\mathbf{2}$ & $\mathbf{1 1 , 1 \%}$ \\
\hline 3. & Tidak Paham & - & - \\
\hline & Jumlah (N) & $\mathbf{1 8}$ & $\mathbf{1 0 0 \%}$ \\
\hline
\end{tabular}

Sumber data : Hasil tabulasi angket item nomor 1
Dari data di atas diketahui bahwa ada 16 guru atau 88,9\% yang menjawab bahwa mereka paham tentang psikologi pembelajaran dan 2 guru atau $11,1 \%$ yang menjawab kurang paham, data tersebut di atas menunjukkan bahwa dari 18 guru yang ada di SMA Muhammadiyah Sungguminasa, ada 2 orang guru yang msih kurang paham tentang psikologi pembelajaran.

Beberapa peran penting psikologi dalam proses pembelajaran yaitu:

1. Memahami siswa sebagai peserta pelajar.

2. Memahami prinsip-prinsip dan teori pembelajaran.

3. Memilih metode-metode pembelajaran.

4. Membantu peserta didik yang kesulitan dalam pembelajaran.

5. Menciptakan situasi pembelajaran dan pengajaran yang kondusif.

6. Memahami dan mengembangkan kepribadian dan profesi guru.

7. Membimbing perkembangan siswa. 


\section{Tingkat Kompetensi Guru \\ Pendidikan Pendidikan Agama}

Islam di SMA Muhammadiyah

\section{Sungguminasa Kabupaten Gowa.}

Kompetensi bukan hanya ada dalam tataran pengetahuan, akan tetapi sebuah kompetensi harus tergambar dalam pola perilaku. Artinya seorang dikatakan memiliki kopetensi apabila ia bukan hanya sekedar tahu tentang sesuatu, akan tetapi bagaimana implikasi dan implementasi pengetahuan itu terlaksana dalam pola perilaku atau tindakan yang dilakukan.

Berikut ini gambaran dalam bentuk tabulasi angket tentang bagaimana tingkat kompetensi guru Pendidikan Agama Islam di SMA Muhammadiyah Sunggumisa Kabupaten Gowa, sebagai berikut :

\section{Tabel III}

Daftar Distribusi Frekuensi

Tanggapan Responden Guru Tentang Guru PAI

\begin{tabular}{|l|l|c|l|}
\hline NO & $\begin{array}{l}\text { Alternatif } \\
\text { Jawaban }\end{array}$ & Frekuensi & $\begin{array}{l}\text { Persen } \\
\text { tase } \\
(\boldsymbol{\%})\end{array}$ \\
\hline 1. & Ya & $\mathbf{1 7}$ & $\mathbf{9 4 , 4 \%}$ \\
\hline 2. & $\begin{array}{l}\text { Kadang- } \\
\text { Kadang }\end{array}$ & $\mathbf{1}$ & $\mathbf{5 , 6 \%}$ \\
\hline 3. & $\begin{array}{l}\text { Tidak } \\
\text { Pernah }\end{array}$ & - & - \\
\hline
\end{tabular}

\begin{tabular}{|l|l|c|c|}
\hline & $\begin{array}{l}\text { Jumlah } \\
\text { (N) }\end{array}$ & 18 & $100 \%$ \\
\hline
\end{tabular}

Sumber data : Hasil tabulasi angket item nomor 4

Dari data di atas diketahui bahwa ada 17 guru atau 94,4\% yang menjawab bahwa Guru PAI di SMA Muhammadiyah Sungguminasa memberikan pembelajaran yang sesuai dengan tujuan pendidikan nasional dan 1 guru atau 6,4 \% yang menjawab kadang-kadang, data tersebut di atas menunjukkan bahwa dari 18 guru yang ada di SMA Muhammadiyah Sungguminasa, masih ada 1 orang guru yang masih menganggap guru PAI itu memberikan pembelajaran sesuai dengan tujuan pendidikan nasional, masih kadang-kadang.

\section{Pengaruh Penguasaan Psikologi Pembelajaran Terhadap} Peningkatan Kompetensi Guru Pendidikan Agama Islam

Guru Pendidikan Agama Islam, selaku tenaga profesional harus mempelajari psikologi pembelajaran PAI secara mendasar dengan maksud memperoleh pengetahuan tentang berbagai aspek sebagai landasan 
pokok, terutama untuk melaksanakan proses pembelajaran (belajarmengajar). Penguasaan akan psikologi pembelajaran akan mendorong kompetensi-kompetensi yang dimiliki oleh seorang guru untuk ikut meningkat, karena didalam 4 rana kompetensi yaitu kompetensi paedagogik, kompetensi sosial, kompetensi kepribadian, dan kompetensi profesional ini mengandung unsur-unsur psikologi, terutama kompetensi sosial dan kepribadian itu sendiri.

Berikut ini gambaran dalam bentuk tabulasi angket tentang bagaimana pengaruh penguasaan psikologi pembelajaran terhadap peningkatan kompetensi guru Pendidikan Agama Islam di SMA Muhammadiyah Sungguminasa Kabupaten Gowa, sebagai berikut :

Tabel IV

Daftar Distribusi Frekuensi

Tanggapan Responden Guru

\begin{tabular}{|l|l|c|c|}
\hline NO & $\begin{array}{l}\text { Alternatif } \\
\text { Jawaban }\end{array}$ & $\begin{array}{l}\text { Freku } \\
\text { ensi }\end{array}$ & $\begin{array}{l}\text { Persentase } \\
\mathbf{( \% )}\end{array}$ \\
\hline 1. & Ya & $\mathbf{1 7}$ & $\mathbf{9 4 , 4 \%}$ \\
\hline 2. & $\begin{array}{l}\text { Kadang- } \\
\text { Kadang }\end{array}$ & $\mathbf{1}$ & $\mathbf{5 , 6 \%}$ \\
\hline 3. & $\begin{array}{l}\text { Tidak } \\
\text { Pernah }\end{array}$ & - & - \\
\hline
\end{tabular}

\begin{tabular}{|c|c|c|c|}
\hline $\begin{array}{c}\text { Jumlah } \\
(\mathbf{N})\end{array}$ & 18 & $100 \%$ \\
\hline
\end{tabular}

Sumber data : Hasil tabulasi angket item nomor 8

Dari data di atas diketahui bahwa ada 17 guru atau 94,4\% yang menjawab bahwa dengan menguasasi psikologi pembelajaran dapat meningkatkan kompetensi guri PAI dan 1 guru atau 6,4 \% yang menjawab kadang-kadang, data tersebut di atas menunjukkan bahwa dari 18 guru yang ada di SMA Muhammadiyah Sungguminasa Kabupaten Gowa, masih ada 1 orang guru yang menganggap bahwa psikologi tidak selamanya dapat meningkatkan kompetensi guru PAI.

\section{KESIMPULAN}

Berdasarkan pada uraian di atas, maka pada bab ini penulis mengemukakan beberapa kesimpulan antara lain :

1. Penguasaan psikologi pembelajaran guru Pendidikan Agama Islam di SMA Muhammadiyah Sungguminasa Kabupaten Gowa yaitu, penguasaan psikologi pembelajaran, mulai dari memahami siswa sebagai pelajar, 
memilih metode yang sesuai keadaan peserta didik, membantu peserta didik yang kesulitan dalam belajar dan lain sebagainya , sangat dituntut untuk dimiliki oleh seorang guru, agar seorang guru dapat menciptakan suasana pembelajaran yang kondusif dan efektif.

2. Tingkat kompetensi guru Pendidikan Agama Islam di SMA Muhammadiyah Sungguminasa Kabupaten Gowa yaitu sudah baik, terbukti dari pemahaman guru tersebut tentang 4 rana kompetensi ( paedagogik, sosial, kepribadian, dan profesional) yang cukup luas dan penilaian yang mencapai 97, $6 \%$ atau 16 orang guru menjawab baik.

3. Pengaruh psikologi pembelajaran terhadap peningkatan kompetensi guru Pendidikan Agama Islam di SMA Muhammadiyah Sungguminasa Kabupaten Gowa yaitu bahwa ternyata Kompetensi tanpa penguasaan psikologi membuat 4 rana kompetensi ini akan sulit untuk tercapai. Hal ini dikarenakan untuk memahami peserta didik, memilih metode mengajar, bergaul dengan sesama guru, menjadi contoh yang baik bagi siswa dan rekan pegawai, semuanya mengandung muatan psikologi. Jadi dapat disimpulkan bahwa penguasaan psikologi pembelajaran guru Pendidikan Agama Islam sangat berpengaruh dalam peningkatan kompetensinya.

\section{DAFTAR PUSTAKA}

Arikunto Suharsimi, 2010. Prosedur Penelitian Suatu Pendekatan Praktik. Edisi Revisi Jakatra: Rineka Cipta.

Agus Wibowo, dkk. 2012. Menjadi Guru Berkarakter: Strategi Membangun Kompetensi dan Karakter Guru. Yogyakarta: Pustaka Pelajar.

Azhar Basyir, Ahmad. Dkk.1994. Ijtihad Dalam Sorotan. Cet. III. Mizan: Bandung

Bungin, M Burhan. 2013. Metode Penelitian Sosial dan Ekonomi Faktor - Faktor Kuantitatif dan Kualitatif untuk Studi Sosioligi, Kebijakan Publik, Komunikasi, Menajemen, dan Pemasaran. Cet.1. KENCANA

Daradjat, Zakiah. 2001. Metodologi Pengajaran Agama Islam. PT. Bumi Aksara: Jakarta 
Fathurrahman, Pupuh dan Sutikno, Sobry. 2007. Startegi Belajar Mengajar. Cet.1. PT. Refika Aditama: Bandung

Hartuti,Pudji. 2000. Mengembangkan Kepribadiyan dan Mengubah Perilaku Anak Agar Siap Menghadapi Tantangan Global. Cet.1. CV.Citra Malang: Malang

Hamalik Oemar, 2004. Pendidikan Guru Berdasarkan Pendekatan Kompetensi (Cet. III; Jakarta: PT. Ciputat Press). h. 104.

Majid, Abdul, 2005. Pendidikan Agama Islam Berbasis Kompetensi, Bandung : PT. Remaja Rosda Karya.

Majid Abdul. 2004. Pendidikan Agama Islam Berbasis Kompetensi, Bandung: PT Remaja Rosdakarya) Cet. Ke-1, h. 135.

Nata, Abuddin. 1993. Al-Qur'an dan Hadits. Cet. 2. PT. Raja Grafindo Persada: Jakarta

Rayon PSG 124 UNM, 2012. Kebijakan Pengembangan Profesi Guru, Jakarta.

Ramayulis, 2004. Ilmu Pendidikan Islam, (Cet. IV; Jakarta: Kalam Mulia)

Razak, Nasruddin. 1997. Dienul Islam. PT.Alma'arif: Bandung

Sardiman.A. M. 2012. Interaksi dan Motivasi Mengajar. Cet.12. PT. Raja Grafindo Persada: jakarta
Slameto. 2003. Belajar dan Faktor Faktor Yang Mempengaruhinya. PT. Asdi Maha Satnya: Jakarta

Sugiyono. 2012. Metode penelitian pendidikan pendekatan kuantitatif, kualitatif, dan $R \& D . \quad$ ALFABETA,cv: Bandung

Suyanto, dkk, 2013. Menjadi Guru Profesional. Jakarta: Erlangga.

Tafsir Ahmad, 2004. Ilmu Pendidikan Dalam Perspektif Islam, (Cet. IV; Bandung: PT. Remaja Rosda Karya).

Tohirin, 2011. Psikologi Pembelajaran Pendidikan Agama Islam, ( Cet. IV; Jakarta : PT. RajaGrafindo Persada).

Uhbiyati, Nur. 1997. Ilmu Pendidikan Islam (IPI). Cet. I.Pustaka Setia: Bandung

Undang undang Republik Indonesia No 20 Tahun 2003 tentang Sistem Pendidikan Nasional. Cet.1. 2003. Jakarta: Indonesia Legal Center Publishing

Undang undang Republik Indonesia No 14 Tahun 2005 tentang Guru dan Dosen. Cet.1. 2008. Jakarta: Indonesia Legal Center Publishing

Usman,Husaini dan Akbar,Purnomo Setiady.2003.Metodelogi Penelitian Sosial. Ct.4.PT. Bumi Aksara: Jakarta 